\title{
Erratum to: What Does the Data Show for Primary Ovarian Insufficiency?
}

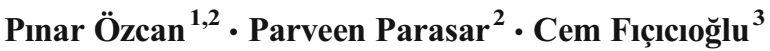

Published online: 9 March 2017

(C) Springer Science+Business Media New York 2017

\section{Erratum to: Curr Obstet Gynecol Rep}

DOI 10.1007/s13669-017-0191-5

The name of author was incorrectly published as "Parveen Parvasar" based on the accepted manuscript received.

With this, the authors corrected this as "Parveen Parasar" as presented above.

The original article was corrected.

The online version of the original article can be found at doi: http://dx.doi. org/10.1007/s13669-017-0191-5

Pınar Özcan

POZCAN@partners.org; drpinarozcan@hotmail.com

1 Department of Obstetrics and Gynecology, Faculty of Medicine, Bezmialem University, İstanbul, Turkey

2 Division of Reproductive Endocrinology and Infertility, Department of Obstetrics, Gynecology and Reproductive Biology, Brigham and Women's Hospital, Harvard Medical School, 75 Francis Street, Boston, MA 02115, USA

3 Division of Reproductive Endocrinology and Infertility, Department of Obstetrics and Gynecology, Yeditepe University, Faculty of Medicine, Istanbul, Turkey 